\title{
An Overview on the Photocatalytic Degradation of Organic Pollutants in the Presence of Cerium Oxide $\left(\mathrm{CeO}_{2}\right)$ Based Nanoparticles: A Review
}

\author{
Tigabu Bekele Mekonnen \\ Department of Chemistry, Mekdela Amba University, Tuluawuliya, Ethiopia
}

Email address:

tgbekele19@gmail.com

\section{To cite this article:}

Tigabu Bekele Mekonnen. An Overview on the Photocatalytic Degradation of Organic Pollutants in the Presence of Cerium $\left.\mathrm{Oxide}_{(\mathrm{CeO}}\right)$ Based Nanoparticles: A Review. Nanoscience and Nanometrology. Vol. 7, No. 1, 2021, pp. 14-26. doi: 10.11648/j.nsnm.20210701.12

Received: January 28, 2021; Accepted: March 17, 2021; Published: April 20, 2021

\begin{abstract}
Considerable efforts have been devoted to enhancing the photocatalytic activity and solar energy utilization of photocatalysts. Photocatalysis has attracted much attention in recent years due to its potential in solving energy and environmental issues. The fabrication of various materials (coupled or doped) to form heterojunctions provides an effective way to better harvest solar energy and to facilitate charge separation and transfer, thus enhancing the photocatalytic activity and stability. Efficient light absorption and charge separation are two of the key factors for the exploration of high performance photocatalytic systems, which is generally difficult to be obtained in a single photocatalyst. In this review, we briefly summarizes the recent development heterostructured semiconductors, including the preparation and performances of semiconductor/semiconductor junctions, semiconductor/metal junctions, and their mechanism in the area of environmental remediation and water splitting for enhanced light harvesting and charge separation/transfer, describe some of the progress and resulting achievements, and discuss the future prospects. The scope of this review covers a variety of type photocatalysts, focusing particularly on Ceria $\left(\mathrm{CeO}_{2}\right)$ heterostructured photocatalysts. We expect this review to provide a guideline for readers to gain a clear picture of fabrication and application of different type heterostructured photocatalysts.
\end{abstract}

Keywords: Nanotechnology, AOPs, Nanoparticle, Ceria, Heterostructure, Photocatalyst, Coupling

\section{Introduction}

Due to the development of various industries in modern society, water pollution has become one of the most serious environmental problems. Polluted water not only affects the ecological system, causing damages to the livings in water and those relying on the aquatic animals and plants, but also threatens human beings. One of the most common contaminants in wastewater is organic substances, most of which are very stable in natural environment [1]. Hence, they can aggregate in wastewater and are therefore harmful to the aquatic ecosystem. Unfortunately, many industries are producing organic pollutants containing wastewater, which aggravates the water pollution problems [2]. Dye wastes represent one of the most problematic groups of pollutants because they can be easily identified by the human eye and are not easily biodegradable. Generally dyes are very stable to light and oxidation due to the complex aromatic molecular structures, but this causes damage to the environment and dramatically threatens human health [3-5]. Therefore, how to treat wastewater, especially removing organic pollutants in wastewater is one of the most crucial problems for sustainable development [6].

Various conventional treatment methods for dye removal from wastewater include physical, chemical and biological processes such as, anaerobic treatment, trickling filters, flotation, chemical coagulation, electrochemical coagulation, membrane separation, which have been studied so far [7]. However, the main disadvantages of these methods include the production of toxic sludge, high operational cost, technical limitations, lack of effective color reduction and sensitivity to a variable wastewater input. It is also a problem because these dye compounds in wastewater ordinarily contain one or several benzene ring and cannot be decomposed easily in chemical and biological processes. Moreover, most of the dyes are found to be resistant to 
normal treatment process.

The use of solar energy and semiconductor catalysts for photocatalytic degradation of organic dyes in water has been intensively investigated as an emerging renewable technology [8-11]. Photocatalysis is one of the advanced oxidation process (AOP) considered as an efficient, stable, and environmentally friendly method in the field of environmental pollution control [12]. It is known that the photocatalysis process can proceed under UV-light or/and visible-light irradiation. Under light irradiation, the organic contaminants can be partially degraded to smaller molecules or even completely mineralized to $\mathrm{CO}_{2}$ and $\mathrm{H}_{2} \mathrm{O}$ [13]. Since visible-light occupies much higher spectral power within solar spectrum than UV-light, visible-light prompted photocatalysis is more advantageous for its efficient utilization of the solar irradiation [14]. Therefore, developing a photocatalyst that can efficaciously degrade organic contaminants under visible-light irradiation is a highly promising direction in the application of wastewater treatment.

Several semiconductor photocatalysts are being used for the treatment of waste water pollutants. Among them $\mathrm{TiO}_{2}$, $\mathrm{ZnO}, \mathrm{CeO}_{2}, \mathrm{CdS}, \mathrm{Ag}_{3} \mathrm{PO}_{4}$ etc... has been reported as a new $\mathrm{UV}$ or visible-light-driven photocatalyst for the oxidation of water and photodecomposition of organic compounds [1519].

Band gap modifications can be carried out by using several approaches such as doping of metal and non-metal elements, metal-metal co-doping, nonmetal-nonmetal co-doping, metalnonmetal co-doping [20], tri-doping, dye sensitization, deposition of noble metals, and making composite photocatalyst by forming heterojunctions [21-26]. Among the various techniques for the enhancement of visible light effective photocatalysis, composite photocatalysts have drawn more attention owing to their significant increase in photocatalytic activity. Formation of heterojunction between two semiconductors allows the interaction of the band structure which effectively prevents the electron hole recombination thereby enhance the photocatalytic activity $[23,27]$.

\section{Nanostructured Semiconductors}

Applying the concept of nanotechnology to heterogeneous catalysis helps us to understand more accurately the transformations occurring on the catalyst's surface at a molecular level. The synthesis of materials with nanometric dimensions will facilitate a better understanding of the reaction mechanisms as well as to design novel useful catalytic systems. Nanostructured photocatalysts offer large surface to volume ratios allowing higher adsorption of the target molecules. Intensive research over the past decade for its implementation in the purification of drinking water can be found in the literature [28, 29]. Photocatalysis, using nanostructures of metal oxide semiconductors like zinc oxide $(\mathrm{ZnO})$, titania $\left(\mathrm{TiO}_{2}\right)$ and ceria $\left(\mathrm{CeO}_{2}\right)$ can be an attractive way of water purification as it is capable of removing chemical as well as biological contaminants [30-32]. A good photocatalyst should absorb light efficiently preferably in the visible or near UV part of the electromagnetic spectrum.

\subsection{Properties of $\mathrm{CeO}_{2}$ Nanoparticles}

Ceria, which is semiconducting, abundant, nontoxic, and inexpensive, is widely applied in heterogeneous catalytic reactions due to the high mobility of oxygen species and reversible transition between $\mathrm{Ce}^{4+}$ and $\mathrm{Ce}^{3+}$ oxidation states in $\mathrm{CeO}_{2}$ crystal. Recent researches have revealed that the size, morphology, surface structure, and synergistic interaction dramatically influence the catalytic performance of $\mathrm{CeO}_{2}$ [33]. $\mathrm{CeO}_{2}$ has been shown to be a particularly effective catalyst, in part due to the redox potential of the $\mathrm{Ce}^{4+} / \mathrm{Ce}^{3+}$ couple, as well as its resistance to chemical and photocorrosion, and strong light absorption in the UV region (absorption edge 385-400 $\mathrm{nm}$ ). Unfortunately the large band gap $(3.2 \mathrm{eV})$ limits further application of $\mathrm{CeO}_{2}$ [34]. From the AM1.5 spectrum, it can be seen that UV light only composes, $3-5 \%$ of the photon flux reaching the earth's surface, while around $45 \%$ is in the visible light range. Although photocatalytic activity of $\mathrm{CeO}_{2}$ has been investigated intensively, the broad band gap energy of this material limits its further application in the visible light region. Hence, efforts have been devoted to improve the light-harvesting capability and photocatalytic activity either by doping or/and coupling with other narrow band gap semiconductors and extend the light absorption of $\mathrm{CeO}_{2}$ to the visible light region.

\subsection{Properties of $\mathrm{Ag}_{3} \mathrm{PO}_{4}$ Nanoparticles}

The development of efficient photocatalysts is very important and desirable in environmental pollution mediation and solar energy conversion.

Among the new materials, silver phosphate $\left(\mathrm{Ag}_{3} \mathrm{PO}_{4}\right)$ was reported as a high quantum yield photocatalyst to promote the generation of $\mathrm{O}_{2}$ in water splitting, because $\mathrm{Ag}_{3} \mathrm{PO}_{4}$ has appropriate band gap of $2.45 \mathrm{eV}$ for efficient absorption of visible light whose wavelength is shorter than $530 \mathrm{~nm}$ [35]. Moreover, the most interesting is that this novel photocatalyst can achieve a quantum efficiency of up to $90 \%$ at wavelengths greater than $420 \mathrm{~nm}$, which is significantly higher than the previous reported values. The effects of particle size [36], pH value [37] and morphology [38] of silver phosphate on its photocatalytic activity have also been investigated.

Despite the fact that $\mathrm{Ag}_{3} \mathrm{PO}_{4}$ is a promising candidate for environmental remediation and renewable energy, the consumption of a large amount of noble metal and the low structural stability of pure $\mathrm{Ag}_{3} \mathrm{PO}_{4}$ strongly limits its practical environmental applications. Unfortunately, one major limitation of this novel photocatalyst is the instability upon photo-illumination, since it is easily corroded by the photogenerated electrons;

$\left(4 \mathrm{Ag}_{3} \mathrm{PO}_{4}+6 \mathrm{H}_{2} \mathrm{O}+12 \mathrm{~h}^{+}+12 \mathrm{e}^{-} \rightarrow 12 \mathrm{Ag}+4 \mathrm{H}_{3} \mathrm{PO}_{4}+3 \mathrm{O}_{2}\right)[39](1)$ 


\subsection{Properties of CdS Nanoparticles}

Cadmium sulphide (CdS) is a brilliant II-VI semiconductor material with a direct band gap of $2.42 \mathrm{eV}$ at room temperature with many outstanding physical and chemical properties, which has promising applications in multiple technical fields including photochemical catalysis, gas sensor, detectors for laser and infrared, solar cells, nonlinear optical materials, various luminescence devices, optoelectronic devices and so on [40]. Cadmium sulphide (CdS) has excellent visible light detecting properties among the others semiconductors. The photocatalytic activity of $\mathrm{CdS}$ is mainly dependent on the electrons and holes which are produced by light absorption.

Photocatalytic process is a photoreaction with a catalyst and depends on the nature of the catalyst because of its ability to create electron-hole pairs, which generate free radicals having the ability to undergo secondary reactions. Preethy et al. reported the synthesis of $\mathrm{CdS}$ nanoparticles with photocatalytic activity under visible light. The particle with photoactivity under visible light has wide application in textile and food processing industries [41].

\section{Photocatalytic Application of Ceria and Ceria-Based Nanoparticles}

Cerium dioxide $\left(\mathrm{CeO}_{2}\right)$, as a fascinating rare earth material, has attracted much attention owing to its high activity, low cost and environmentally friendly properties [42, 43]. It shows promising photoactivity for the degradation of organic pollutants and water splitting for hydrogen generation [44]. Nevertheless, pristine $\mathrm{CeO}_{2}$ can only be excited by ultraviolet light (UV) because of its wide band gap (about $3.2 \mathrm{eV}$ ), limiting its further application in the visible light region [45].

In order to highly utilize solar energy, various methods, such as doping, noble metal deposition and forming composites have been designed to enhance the absorption of $\mathrm{CeO}_{2}$ photocatalysts in the visible light region. Among them, the most effective strategy is the coupling of two semiconductors, $\mathrm{CeO}_{2}$ and another semiconductor, to form a composite [46-48]. So far, various $\mathrm{CeO}_{2}$-based composites with a visible light response, such as $\mathrm{CdS} / \mathrm{CeO}_{2}$ [49], $\mathrm{CeO}_{2} / \mathrm{Ag}_{3} \mathrm{PO}_{4}$ [50], $\mathrm{CeO}_{2} / \mathrm{ZnO}$ [51], $\mathrm{TiO}_{2} / \mathrm{CeO}_{2}$ [52], $\mathrm{TiO}_{2} / \mathrm{CeO}_{2} / \mathrm{ZnO}$ [53] and $\mathrm{CdS} / \mathrm{CeO}_{2} / \mathrm{Ag}_{3} \mathrm{PO}_{4}$ [54] etc... composite heterostructure appear to be very efficient for the photodecomposition of organic dye than single $\mathrm{CeO}_{2}$ photocatalysts. The coupled semiconductor with a narrow band gap usually acts as a visible light sensitizer, and the photogenerated electrons or holes excited by visible light irradiation will transfer to the $\mathrm{CeO}_{2}$. Thus the high efficiency of the interfacial charge transfers as well as the stronger visible light absorption capacity results in the enhanced activity of the composite photocatalysts $[55,56]$.

\subsection{Photocatalytic Activities of Prestine $\mathrm{CeO}_{2}$ Nanoparticle}

As for pure $\mathrm{CeO}_{2}$, it has been investigated under UV irradiation concerning water splitting for the generation of hydrogen gas [57] and photodegradation of toluene in the gas phase [58]. Zhai et al. and Salker and Borker have recently reported the photocatalytic behaviors of $\mathrm{CeO}_{2}$ under sunlight irradiation to degrade dyes $[59,60]$. Herein, we report $\mathrm{CeO}_{2}$ for photocatalytic degradation of sulfo group-containing azo dyes in aqueous suspension irradiated by visible light. Different azo dye was chosen as model target to examine the adsorption and degradation of azo dye on $\mathrm{CeO}_{2}$ irradiated by visible light. The $\mathrm{CeO}_{2}$ showed high photoactivity towards degradation of azo dye and has been proven to be a promising alternative for dye containing wastewater treatment under visible light irradiation.

$\mathrm{Ji}$ et al. reported the photodegradation of $\mathrm{AO} 7$ by aqueous $\mathrm{CeO}_{2}$ dispersion under visible light illumination at wavelengths longer than $420 \mathrm{~nm}$ [43]. The data displayed in Figure $1 \mathrm{~A}$ clearly indicates that the photocatalytic activity of $\mathrm{CeO}_{2}$ to degrade azo dye acid orange 7 (AO7) was found to have better performance than commercial reference P25. The temporal UV/Vis spectra showed that the AO7 characteristic band centered at $485 \mathrm{~nm}$ decreased promptly upon light irradiation (Figure 1B), indicating that at least the chromophore structure of the dye was destroyed. Peaks at 310 and $228 \mathrm{~nm}$ corresponding to naphthalene ring and benzene ring in the dye molecule were also reduced partly, showing a variety of organic molecules present in the solution even after the dispersion is totally bleached [28].
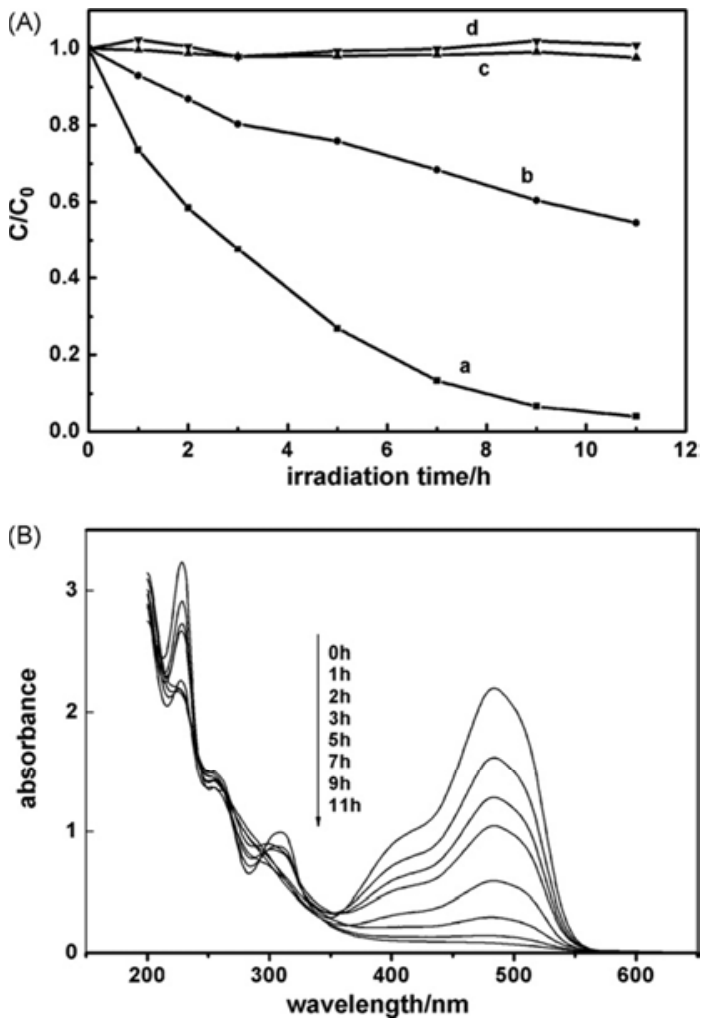

Figure 1. (A) Temporal course of the photodegradation of $\mathrm{AO} 7$ in $\mathrm{CeO}_{2}$ aqueous dispersions under visible light irradiation: (a) $\mathrm{CeO}_{2}$ under visible irradiation $(\lambda>420 \mathrm{~nm})$. (b) $\mathrm{TiO}_{2}$ under irradiation $(\lambda>420 \mathrm{~nm})$. (c) $\mathrm{No}$ catalyst. (d) $\mathrm{CeO}_{2}$ in the dark. (B) UV/Vis spectral changes recorded for (a) as a function of irradiation time. 


\subsection{Photocatalytic Activities of $\mathrm{CeO}_{2} / \mathrm{Ag}_{3} \mathrm{PO}_{4}$ Nanoparticle}

$\mathrm{Ag}_{3} \mathrm{PO}_{4}$ is a p-type semiconductor with indirect and direct band gaps are $2.36 \mathrm{eV}$ and $2.43 \mathrm{eV}$, respectively [61]. On account of that the combination of $\mathrm{CeO}_{2}$ and $\mathrm{Ag}_{3} \mathrm{PO}_{4}$ possess well matched overlapping band structure [62], p-n heterojunctions could be fabricated by coupling $\mathrm{CeO}_{2}$ with $\mathrm{Ag}_{3} \mathrm{PO}_{4}$, which will bring more effective interface transfer of photogenerated electrons and holes to restrain the recombination. Besides, owe to its narrower band gap relative to $\mathrm{CeO}_{2}$, $\mathrm{Ag}_{3} \mathrm{PO}_{4}$ is able to act as efficient photosensitizer to enlarge the light response range under solar light irradiation.

For example Zhang et al. studied the photocatalytic activities of $\mathrm{Ag}_{3} \mathrm{PO}_{4} / \mathrm{CeO}_{2}$ by using Rhodamine $\mathrm{B}(\mathrm{RhB})$ as a model pollutant under visible light irradiation [63]. It can be

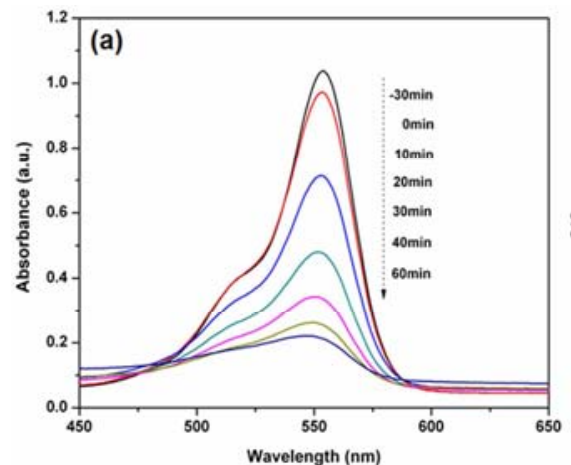

seen that $88.0 \%$ of the $\mathrm{RhB}$ is photocatalitcally degraded after 60 min irradiation for the $\mathrm{Ag}_{3} \mathrm{PO}_{4} / \mathrm{CeO}_{2}$ composite. As shown in Figure 2, the photocatalytic activity of the $\mathrm{Ag}_{3} \mathrm{PO}_{4}$ and $\mathrm{CeO}_{2}$ sample for $\mathrm{RhB}$ degradation is much lower than that of the $\mathrm{Ag}_{3} \mathrm{PO}_{4} / \mathrm{CeO}_{2}$ p-n heterojunctions. For the pure $\mathrm{Ag}_{3} \mathrm{PO}_{4}$ and $\mathrm{CeO}_{2}$ samples, the $\mathrm{RhB}$ is degraded by only $47.0 \%$ and $10 \%$, respectively. The absorption spectra of $\mathrm{RhB}$ (Figure $2 \mathrm{a}$ ), with $0.1 \mathrm{~g}$ of the $\mathrm{CeO}_{2} / \mathrm{Ag}_{3} \mathrm{PO}_{4} \mathrm{p}$-n heterojunction photocatalyst under visible light irradiation, clearly show that the characteristic absorption peaks corresponding to $\mathrm{RhB}$ decrease rapidly as the exposure time increases, indicating the decomposition of $\mathrm{RhB}$ and the significant reduction in the $\mathrm{RhB}$ concentration.

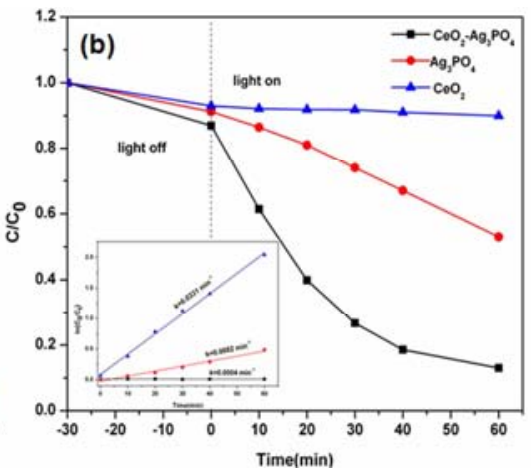

Figure 2. UV-Vis absorbance spectra of $\mathrm{RhB}$ solution after photocatalytic degradation with $\mathrm{CeO}_{2} / \mathrm{Ag}_{3} \mathrm{PO}_{4}$ heterojunction (a) and $\mathrm{RhB}$ concentration $\mathrm{C}_{t} / \mathrm{C}_{0}$ and $\ln \left(\mathrm{C}_{0} / \mathrm{C}_{t}\right)$ (inset) vs. time with $\mathrm{CeO}_{2}, \mathrm{Ag}_{3} \mathrm{PO}_{4}$ and $\mathrm{CeO}_{2} / \mathrm{Ag}_{3} \mathrm{PO}_{4}$ (b) under visible light irradiation.

In addition, Song et al. found that the pure $\mathrm{CeO}_{2}$ hardly shows photocatalytic activity under the visible light illumination for $\mathrm{MB}$ [50]. After $18 \mathrm{~min}$ of the visible-light irradiation, the pure $\mathrm{Ag}_{3} \mathrm{PO}_{4}$ shows good photocatalytic performance, and its photocatalytic degradation efficiency of $\mathrm{MB}$ is about $76 \%$. The $\mathrm{CeO}_{2} / \mathrm{Ag}_{3} \mathrm{PO}_{4}$ (1 wt. \%) composite degrades relatively high level of $\mathrm{MB}(88 \%)$, which is increased by $12 \%$ in comparison with the pure $\mathrm{Ag}_{3} \mathrm{PO}_{4}$. As $\mathrm{Ag}_{3} \mathrm{PO}_{4}$ is combined with $\mathrm{CeO}_{2}$, the photocatalytic activity has some improvement, which illustrates that the introduction of $\mathrm{CeO}_{2}$ is an effective method for the enhancement of photocatalytic performance of the pure $\mathrm{Ag}_{3} \mathrm{PO}_{4}$. The improvement of photocatalytic activity for $\mathrm{CeO}_{2} / \mathrm{Ag}_{3} \mathrm{PO}_{4}$ hybrid materials could be attributed to the heterojunction between $\mathrm{CeO}_{2}$ and $\mathrm{Ag}_{3} \mathrm{PO}_{4}$.

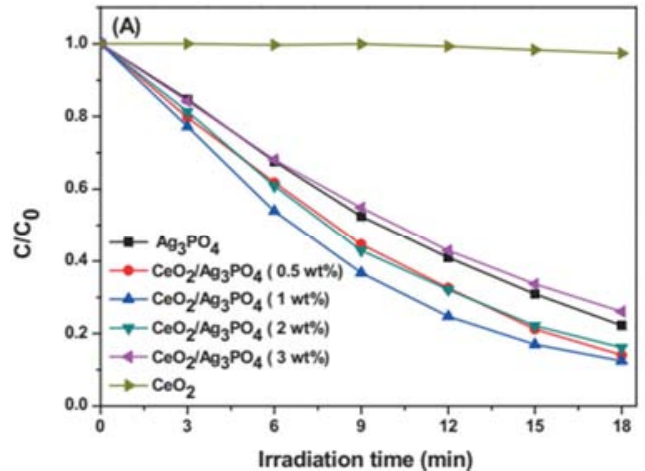

Figure 3. Degradation of $M B$ under the visible light irradiation with $\mathrm{CeO} / \mathrm{Ag}_{3} \mathrm{PO}_{4}$ composites.

\subsection{Photocatalytic Activities of $\mathrm{CdS} / \mathrm{CeO}_{2}$ Nanoparticle}

Cadmium sulfide (CdS), a typical II-VI semiconductor, has been extensively studied as visible-light photocatalyst for $\mathrm{H}_{2}$ evolution and a photosensitizer for sensitizing various wide bandgap metal oxides due to its favorable band-edges more negative than $0 \mathrm{~V}$ (vs. NHE), and suitable band-gap $(2.4 \mathrm{eV})$ corresponding well with the spectrum of sunlight. More importantly, $\mathrm{CdS}$ can couple well with $\mathrm{CeO}_{2}$ due to their matched band structures $[64,65]$. $\mathrm{CdS}$ coupled $\mathrm{CeO}_{2}$ composite materials have been extensively explored in the field of photocatalysis due to its reinforced visible light absorption capacity and microstructure-dependent photocatalytic properties [66]. Tong and co-workers investigated the photocatalytic performance of $\mathrm{CdS} / \mathrm{CeO}_{\mathrm{x}}$ nanowires and $\mathrm{CdS} / \mathrm{CeO}_{2}$ nanospheres prepared by electrochemical process, and found that the both composites exhibited hydrogen evolution rate of 223 and $473.6 \mu \mathrm{molh}^{-1} \mathrm{~g}^{-1}$, respectively, higher than that of pure $\mathrm{CeO}_{2}$ under visible light illumination.

$\mathrm{Gu}$ et al. synthesized $\mathrm{CdS} / \mathrm{CeO}_{2}$ nanoparticles and compare the photocatalytic degradation of sample dye Rhodamine $\mathrm{B}(\mathrm{RhB})$ under the identical conditions [67]. The results of $\mathrm{RhB}$ degradation over $\mathrm{CdS}, \mathrm{CeO}_{2}$ and $\mathrm{CdS} / \mathrm{CeO}_{2}$ photocatalysts were shown in Figure 4. It was noticeable that direct visible light irradiation of the $\mathrm{RhB}$ dye solution in the absence of catalysts was inconsequential toward degrading the dye. The maximum degradation efficiency reached to 
$96.68 \%$ after 48 min for the sample. As expected, all samples showed higher photoactivity for the $\mathrm{RhB}$ degradation than that of pure $\mathrm{CdS}$ and $\mathrm{CeO}_{2}(\lambda \geq 420 \mathrm{~nm})$.

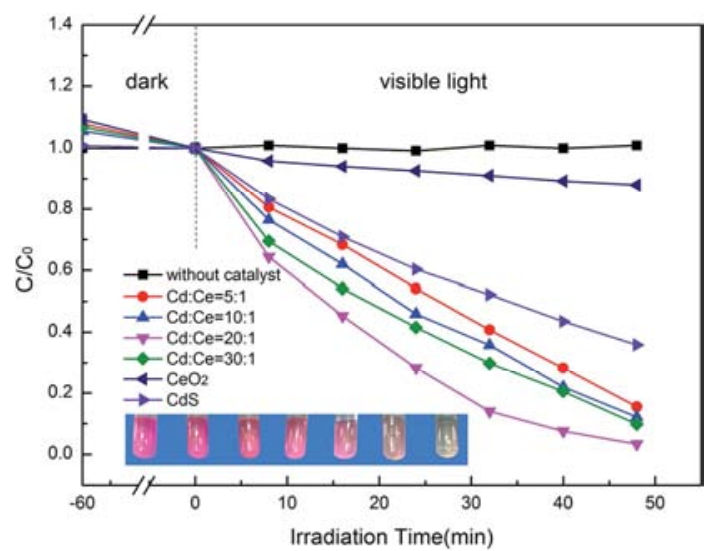

Figure 4. Effect of $\mathrm{CeO}_{2}$ loading on photocatalytic degradation of $\mathrm{RhB}$; the suspensions containing $0.4 \mathrm{~g} / \mathrm{L}$ catalysts, natural $p H=4.3$, initial concentration $=40 \mathrm{mg} / \mathrm{L}, \lambda \geq 420 \mathrm{~nm}$

The excellent photocatalytic performances of $\mathrm{CdS} / \mathrm{CeO}_{2}$ heterostructure for $\mathrm{RhB}$ degradation may be due to that (i) high oxygen storage capacity of $\mathrm{CeO}_{2}$ provided immense

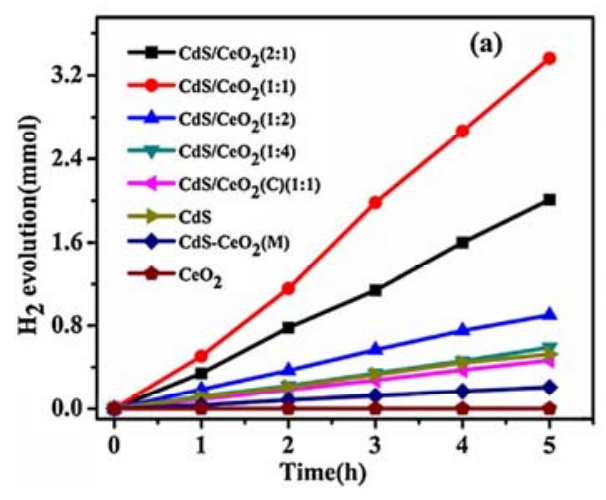

sources of active species; (ii) the strong interactions between $\mathrm{CdS}$ and $\mathrm{CeO}_{2}$ effectively prevented the photo-corrosion and leaching of $\mathrm{CdS}$; and (iii) effective charge separation reduced the recombination rates of electron-hole pairs [67].

You et al. investigated the photocatalytic $\mathrm{H}_{2}$ production activity of the prepared samples tested under visible light irradiation $(>420 \mathrm{~nm})$ [68]. As shown in Figure 5a and b, the $\mathrm{CeO}_{2}$ nanoparticles exhibit no activity for $\mathrm{H}_{2}$ production, which is in accordance with its large bandgap [34]. Coupling with $\mathrm{CdS}$ nanoparticle, the $\mathrm{CdS} / \mathrm{CeO}_{2}$ composites exhibit obvious activities for hydrogen evolution, which even higher than that of the bare $\mathrm{CdS}\left(1.3 \mathrm{mmolh}^{-1} \mathrm{~g}^{-1}\right)$. Particularly, the $\mathrm{CdS} / \mathrm{CeO}_{2}$ composite with a mole ratio (1:1) exhibit the highest $\mathrm{H}_{2}$ evolution rate of $8.4 \mathrm{mmolh}^{-1} \mathrm{~g}^{-1}$, with a high apparent quantum yield (AQY) up to $11.2 \%$, which is about 6.5 times as high as the $\mathrm{CdS}$ nanoparticle. The photocatalytic activities follow the order: $\mathrm{CdS} / \mathrm{CeO}_{2}(1: 1)>\mathrm{CdS} / \mathrm{CeO}_{2}$ $(2: 1)>\mathrm{CdS} / \mathrm{CeO}_{2}(1: 2)>\mathrm{CdS} / \mathrm{CeO}_{2}(1: 4)>\mathrm{CdS}$. The asprepared $\mathrm{CdS} / \mathrm{CeO}_{2}(1: 1)$ composite shows higher activity for $\mathrm{H}_{2}$ evolution and much higher AQY than that of most $\mathrm{CeO}_{2}-$ base composites reported in literatures [69].

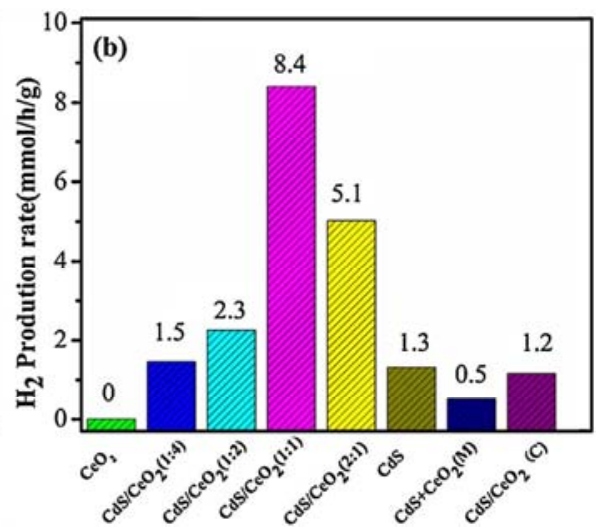

Figure 5. (a) Time-dependent $\mathrm{H}_{2}$ production performance, (b) rate of $\mathrm{H}_{2}$ evolution of bare $\mathrm{CdS}, \mathrm{CeO}_{2}$ and $\mathrm{CdS} / \mathrm{CeO}_{2}$ (n: $m$ ) nanocomposites under visible light irradiation.

\subsection{Photocatalytic Activities of $\mathrm{CeO}_{2} / \mathrm{TiO}_{2}$ Nanoparticles}

Recently, rare-earth elements and their oxides have been combined with $\mathrm{TiO}_{2}$ to improve its photocatalytic activity. Cerium dioxide $\left(\mathrm{CeO}_{2}\right)$ is considered to be a suitable candidate to combine with $\mathrm{TiO}_{2}$ because of its narrow band gap and the $\mathrm{Ce}^{+4} / \mathrm{Ce}^{+3}$ reversible redox couple $[70,71]$. The photocatalytic activities of these composites are obviously enhanced compared with that of $\mathrm{TiO}_{2}$ or $\mathrm{CeO}_{2}$ nanoparticles [72].

Chen et al. reported the degradation of Rhodamine blue ( $\mathrm{RhB}$ ) dye using $\mathrm{CeO}_{2} / \mathrm{TiO}_{2}$ nanocomposite [73]. When the $\mathrm{CeO}_{2} / \mathrm{TiO}_{2}$ nanocomposite was present in the $\mathrm{RhB}$ solution, the decrease of intensity of the $554 \mathrm{~nm}$ peak was greater than that for the solutions with $\mathrm{CeO}_{2}$ nanocubes or $\mathrm{TiO}_{2}$. The absorbance decrease is caused by the cleavage of the conjugated chromophore structure [74], whereas the gradual hypsochromic shift of the absorbance maximum results from stepwise $\mathrm{N}$-deethylation of $\mathrm{RhB}$ during irradiation. Degradation of $\mathrm{RhB}$ by $\mathrm{CeO}_{2} / \mathrm{TiO}_{2}$, $\mathrm{k}$ is $0.012 \mathrm{~min}^{-1}$, which is still much larger than those of the $\mathrm{CeO}_{2}$ nanocubes $(0.004$ $\left.\mathrm{min}^{-1}\right)$ and $\mathrm{TiO}_{2}\left(0.003 \mathrm{~min}^{-1}\right)$. It is believed that the combination of $\mathrm{TiO}_{2}$ and $\mathrm{CeO}_{2}$ in the form of a core shell structure contributes to the improved visible light photocatalytic activity of $\mathrm{CeO}_{2} / \mathrm{TiO}_{2}$ compared with those of $\mathrm{CeO}_{2}$ nanocubes and $\mathrm{TiO}_{2}$.

\section{5. $\mathrm{ZnO} / \mathrm{CeO}_{2}$ Nanoparticle to Enhance Photocatalytic Performance}

Binary $\mathrm{CeO}_{2} / \mathrm{ZnO}$ composites have been reported to be synthesized via various methods, such as atmospheric pressure metal-organic chemical vapor deposition [75], hydrothermal [76], sol-gel method [77] and precipitation technique [78]. The Precipitation method of synthesis is simple, cost-efficient, allows the fabrication of products on a large industrial scale and it provides reproducible results as Nidhi et al. reported [79]. 

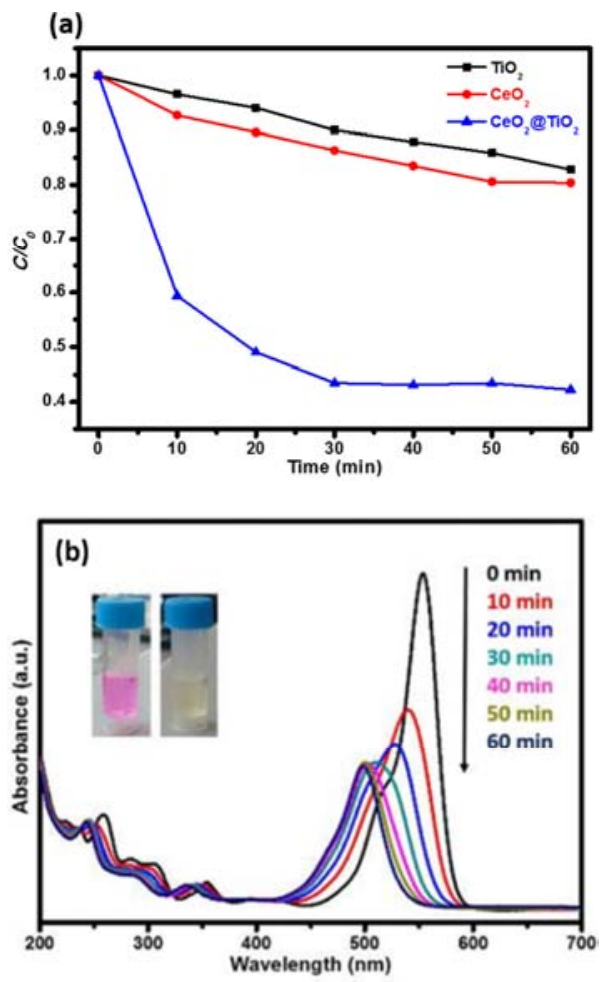

Figure 6. (a) Photodegradation of RhB with various photocatalyst (b) UVVis absorption spectra of solutions of $\mathrm{RhB}$ containing $\mathrm{CeO}_{2} / \mathrm{TiO}_{2}$ nanocomposite under visible light irradiation.

Nidhi et al. compared the photocatalytic activity of $\mathrm{CeO}_{2}$, $\mathrm{ZnO}$ and $\mathrm{CeO}_{2} / \mathrm{ZnO}$ core/shell photocatalysts through the degradation of a basic dye Rhodamine $\mathrm{B}(\mathrm{RhB})$ in an aqueous solution under UV radiation [79]. Figure 7 depicts the degradation of $\mathrm{RhB}$ in the presence of the synthesized core shell composite nanoparticles, under UV radiation at different time. It can be seen that the absorption peaks of $\mathrm{RhB}$ solutions gradually decrease along with irradiation time, which indicates that $\mathrm{RhB}$ in aqueous solutions is decomposed piece by piece under UV light.

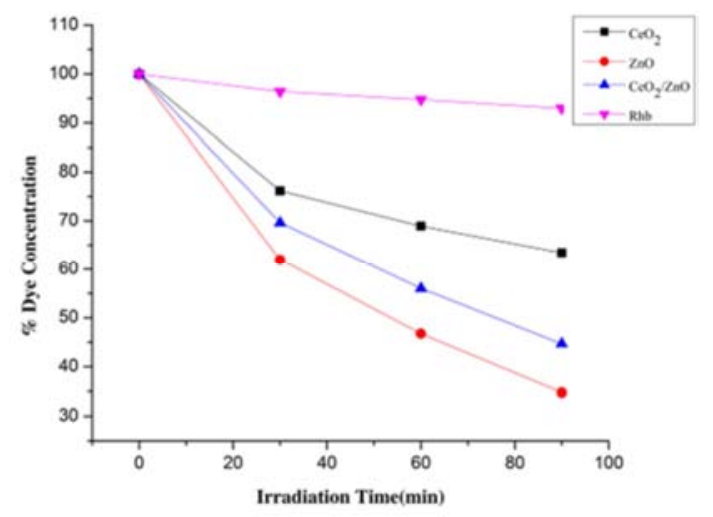

Figure 7. Degradation of RhB with respect to time in presence of photocatalyst.

It could be seen that the degradation ratio of Rhodamine $\mathrm{B}$ in the presence of nano-sized $\mathrm{CeO}_{2}$ powder attains $36.56 \%$ within 90 minutes of exposure to UV light, while it was $65.20 \%$ for $\mathrm{RhB}$ in presence of $\mathrm{ZnO}$ and $55.33 \%$ in presence of composite $\mathrm{CeO}_{2} / \mathrm{ZnO}$ nano-sized photocatalyst, respectively, at the same time. Correspondingly, the degradation ratio of $\mathrm{RhB}$ in the absence of any catalyst under only UV irradiation was only $7.05 \%$ at the same moment. These results indicate that the degradation effects of $\mathrm{RhB}$ in the presence of nano-sized catalyst powders are significant than that of unanalyzed system.

The photocatalytic activities of the pristine $\mathrm{ZnO}$ and $\mathrm{CeO}_{2} / \mathrm{ZnO}$ catalysts were also evaluated in terms of the degradation of methyl orange (MO) under a fluorescent lamp [80]. MO degradation was measured by observing the change in the adsorption spectra of $\mathrm{MO}$ at $464 \mathrm{~nm}$, as shown in Figure 8a. Photocatalysts based on $\mathrm{CeO}_{2} / \mathrm{ZnO}$ showed higher photocatalytic activity, which can degrade $94.06 \%$ of MO after $60 \mathrm{~min}$. In contrast, the photocatalysts based on pristine $\mathrm{ZnO}$ can degrade $69.42 \%$ of MO. The results suggest an improvement of MO photocatalytic degradation due to an increase in Ce ion doping.
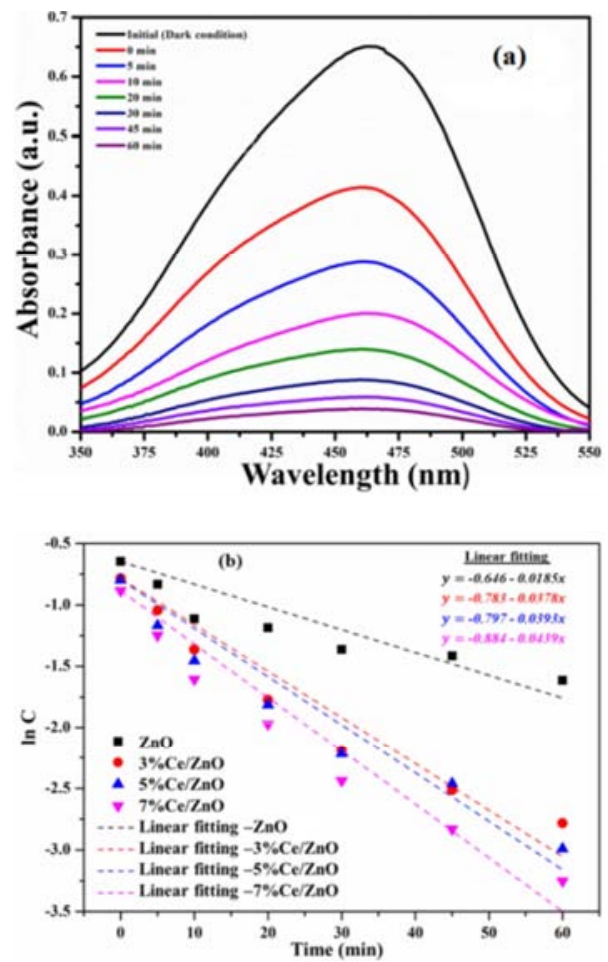

Figure 8. (a) Change in absorption spectra of the $\mathrm{CeO}_{2} / \mathrm{ZnO}$ catalysts (b) First-order kinetic adsorption curves during photodegradation of methyl orange.

\subsection{Photocatalytic Activity of Ceria Based Ternary Nanocomposite}

Nanocomposites such as $\mathrm{g}_{-} \mathrm{C}_{3} \mathrm{~N}_{4} / \mathrm{CeO}_{2} / \mathrm{ZnO}$ [81], $\mathrm{TiO}_{2} / \mathrm{CeO}_{2} / \mathrm{ZnO}$ [53, 82] $\quad \mathrm{CeO}_{2} / \mathrm{ZrO}_{2} / \mathrm{Al}_{2} \mathrm{O}_{3} \quad$ [83] and $\mathrm{CdS} / \mathrm{CeO}_{2} / \mathrm{Ag}_{3} \mathrm{PO}_{4}$ [54] etc... have been considered as effective photocatalysts. The mixing of two different metal oxides leads to not only the thermal stability but also the different physical and chemical property from the individual metal oxides. There are many reports available on mixed metal oxides to improve the thermal stability of Prestine$\mathrm{CeO}_{2}$ and increase the photocatalytic activity $[84,85]$. 


\subsection{1. $\mathrm{g}-\mathrm{C}_{3} \mathrm{~N}_{4} / \mathrm{CeO}_{2} / \mathrm{ZnO}$ Nanocomposite}

Highly efficient $\mathrm{g}-\mathrm{C}_{3} \mathrm{~N}_{4} / \mathrm{CeO}_{2} / \mathrm{ZnO}$ nanocomposite was synthesized by Yuan et al. through pyrolysis and subsequent exfoliation method [81]. To study the synergistic effect of the novel g- $\mathrm{C}_{3} \mathrm{~N}_{4} / \mathrm{CeO}_{2} / \mathrm{ZnO}$ ternary photocatalytic system, the photocatalytic activities of different photocatalysts materials are evaluated for the degradation of methyl blue (MB) solution as a model organic pollutant under irradiation with visible light. Dark adsorption of dye molecules is measured for $20 \mathrm{~min}$ to reach an adsorption-desorption equilibrium. In their work, MB, with a characteristic absorption at $663 \mathrm{~nm}$, is chosen as a typical organic pollutant for testing the photocatalytic activity of the as-prepared products under both $\mathrm{UV}$ and visible light irradiation.
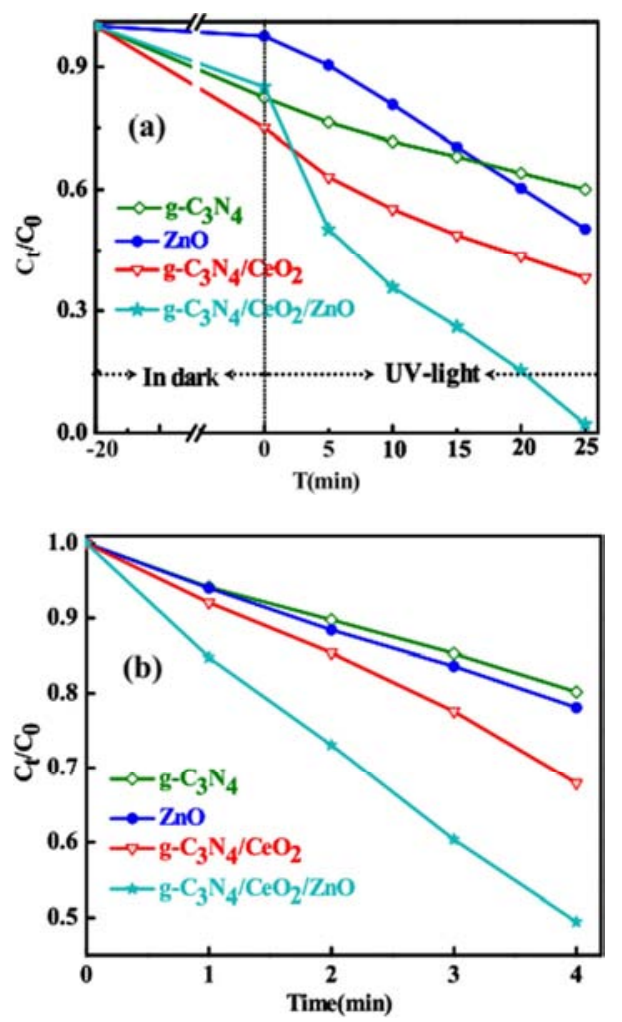

Figure 9. The photocatalytic activity of the as-synthesized photocatalysts under (a) UV light and (b) Visible light.

The sag curves in the first 20 min before light irradiation are caused by the MB adsorption-desorption process on the catalyst surfaces. Yuan et al. seen that only slight decrease (about 3\%) in the concentration of MB can be observed in the presence of $\mathrm{ZnO}$ as the adsorption-desorption equilibrium of $\mathrm{MB}$ on the surface of $\mathrm{ZnO}$ nanoparticles reaches in dark after $20 \mathrm{~min}$ ultrasonic treatment [81]. Whereas, the adsorption ability of MB over g- $\mathrm{C}_{3} \mathrm{~N}_{4}, \mathrm{~g}-\mathrm{C}_{3} \mathrm{~N}_{4} / \mathrm{CeO}_{2}$ and g$\mathrm{C}_{3} \mathrm{~N}_{4} / \mathrm{CeO}_{2} / \mathrm{ZnO}$ is up to $17.6 \%, 25 \%$ and $15 \%$, respectively, which may be attributed to the nanosheets structure with high specific surface area. They can see that about $50.0 \%, 40.1 \%$, $62.0 \%$ and $98.9 \% \mathrm{MB}$ is decomposed after $25 \mathrm{~min} \mathrm{UV}$ light irradiation in the presence of $\mathrm{ZnO}, \mathrm{g}-\mathrm{C}_{3} \mathrm{~N}_{4}, \mathrm{~g}-\mathrm{C}_{3} \mathrm{~N}_{4} / \mathrm{CeO}_{2}$ nanosheets and $\mathrm{g}_{-} \mathrm{C}_{3} \mathrm{~N}_{4} / \mathrm{CeO}_{2} / \mathrm{ZnO}$ ternary nanocomposites, respectively. These results indicate that the formation of $\mathrm{g}$ -
$\mathrm{C}_{3} \mathrm{~N}_{4} / \mathrm{CeO}_{2} / \mathrm{ZnO}$ ternary nanocomposites can greatly enhance the photocatalytic properties on the degradation of pollutants under UV-light irradiation.

The $\mathrm{g}^{-} \mathrm{C}_{3} \mathrm{~N}_{4} / \mathrm{CeO}_{2} / \mathrm{ZnO}$ composite shows the highest photodegradation activity on MB molecules, about $52.0 \%$ of the $\mathrm{MB}$ is photocatalitcally degraded after $4 \mathrm{~h}$ irradiation for the g- $_{3} \mathrm{~N}_{4} / \mathrm{CeO}_{2} / \mathrm{ZnO}$ composite as presented in Figure $9 \mathrm{~b}$. In contrast, the MB is photodegraded by only $22.0 \%, 20.0 \%$ and $32.0 \%$ in the presence of $\mathrm{ZnO}$, pure $\mathrm{g}_{-} \mathrm{C}_{3} \mathrm{~N}_{4}$ and $\mathrm{g}$ $\mathrm{C}_{3} \mathrm{~N}_{4} / \mathrm{CeO}_{2}$ samples, respectively. The possible reason for the visible light photocatalytic activity of $\mathrm{ZnO}$ may be owing to the defects in $\mathrm{ZnO}$ and sensitized effect of dye. The results demonstrate that the degradation efficiency of $\mathrm{g}$ $\mathrm{C}_{3} \mathrm{~N}_{4} / \mathrm{CeO}_{2} / \mathrm{ZnO}$ composite to $\mathrm{MB}$ is much higher than those of pure g- $\mathrm{C}_{3} \mathrm{~N}_{4}, \mathrm{ZnO}$ and $\mathrm{g}-\mathrm{C}_{3} \mathrm{~N}_{4} / \mathrm{CeO}_{2}$ nanosheets under visible light irradiation. Therefore, we can conclude that the formation of the $\mathrm{g}-\mathrm{C}_{3} \mathrm{~N}_{4} / \mathrm{CeO}_{2} / \mathrm{ZnO}$ composite structure facilitates the enhanced photocatalytic activity.

\subsubsection{Photocatalytic Activity of $\mathrm{CeO}_{2} / \mathrm{ZnO} / \mathrm{TiO}_{2}$ Composite}

Prabhu et al. discussed the photocatalytic activity of the composites under visible light irradiation by choosing Rhodamine Blue (RhB) as a model substrate [82]. The photocatalytic activity at $0.2 \mathrm{~g} / \mathrm{L}$ of catalysts amount and 5 $\mathrm{mg} / \mathrm{L}$ of dye concentration was shown in Figure 10. The photocatalytic activity of the catalysts depends on the $\mathrm{TiO}_{2}$ phase present in it. On increasing the percentage of rutile phase in the catalyst, the photocatalytic activity was decreased. The catalyst CZT-A-1 shows high photocatalytic activity as it contains high percentage of anatase phase of $\mathrm{TiO}_{2}$. Even though the band gap of the catalyst can be decreased from 3.13 to $3.01 \mathrm{eV}$ and 3.13 to $2.91 \mathrm{eV}$ by increasing the calcinations temperature and changing the amount of $\mathrm{ZnO}$ and $\mathrm{CeO}_{2}$, the photocatalytic activity cannot be increased because of phase transformation from anatase to rutile. The high calcinations temperature maybe leads to the formation of thermodynamically stable rutile phase in the composite.

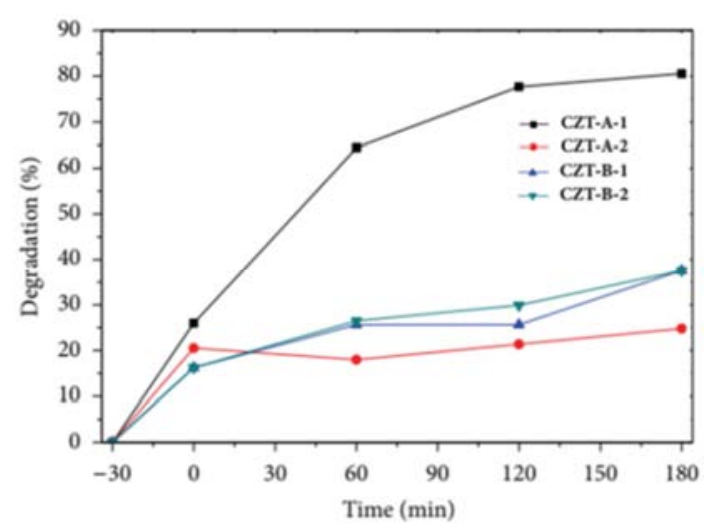

Figure 8. Degradation of RhB by different photocatalyst load.

In addition to this Milenova et al. compared the performance of the mechanochemically treated $\mathrm{TiO}_{2}, \mathrm{CeO}_{2}$, $\mathrm{ZnO}$ and $\mathrm{TiO}_{2} / \mathrm{CeO}_{2} / \mathrm{ZnO}$ photocatalysts in methyl orange (MO) degradation in an aqueous solution [53]. The degrees 
of $\mathrm{MO}$ degradation line become: $\mathrm{TiO}_{2}-\mathrm{MCT}(49 \%)<$ $\mathrm{TiO}_{2} / \mathrm{CeO}_{2} / \mathrm{ZnO}-\mathrm{MCT}(63 \%)<\mathrm{CeO}_{2}-\mathrm{MCT}(67 \%)<\mathrm{ZnO}-$ MCT $(81 \%)$. They assumed that the polar end of MO molecule is irreversibly adsorbed on $\mathrm{TiO}_{2}$ causing thus deactivation. This can explain the plateau observed in the curve of $\mathrm{MO}$ degradation on $\mathrm{TiO}_{2}$ as indicated in the Figure 11. The nonpolar surfaces of $\mathrm{CeO}_{2}$ and $\mathrm{ZnO}$ exclude such behavior [86].

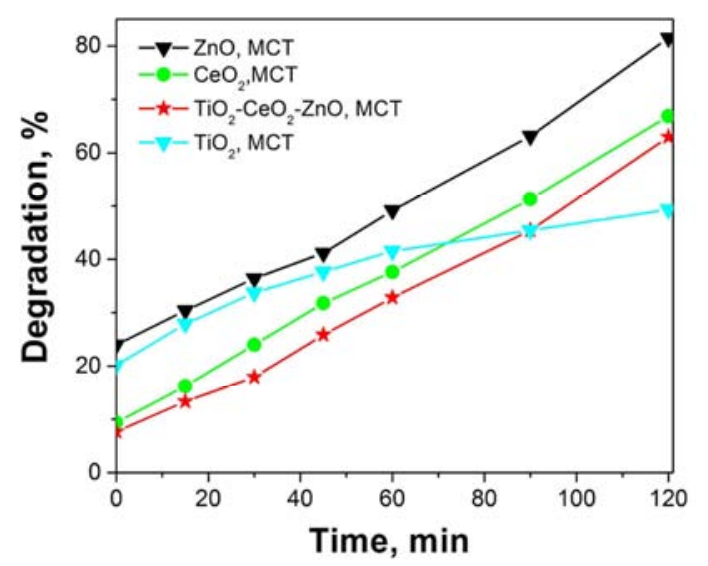

Figure 9. The degradation of the MO dye in water solution with the course of time under $U V$-A illumination at $464 \mathrm{~nm}$ using $\mathrm{TiO}_{2}, \mathrm{CeO}_{2}, \mathrm{ZnO}$ and $\mathrm{TiO}_{2} / \mathrm{CeO}_{2} / \mathrm{ZnO}$ photocatalysts.

\subsubsection{Photocatalytic Behavior of Ternary $\mathrm{CdS} / \mathrm{CeO}_{2} / \mathrm{Ag}_{3} \mathrm{PO}_{4}$ Photocatalysts}

\section{i. Photocatalytic Activity}

Abi M. Taddesse et al. synthesized ternary $\mathrm{CdS} / \mathrm{CeO}_{2} / \mathrm{Ag}_{3} \mathrm{PO}_{4}(1: 1,2: 1,3: 1$ and 4:1 molar ratios) under appropriate conditions [54]. The result exhibited that the highest photocatalytic activity was recorded in case of ternary nanocomposite when compared with both single $\left(\mathrm{CeO}_{2}, \mathrm{CdS}\right.$ and $\left.\mathrm{Ag}_{3} \mathrm{PO}_{4}\right)$ and binary $\left(\mathrm{CdS} / \mathrm{CeO}_{2}\right.$ and $\left.\mathrm{CeO}_{2} / \mathrm{Ag}_{3} \mathrm{PO}_{4}\right)$ congeners see Figure 12a. The reason for the enhancement of ternary nanocomposite is that having more than one path for the formation of electron-hole pair because of the three different interfaces and the delayed electron-hole pair recombination $[87,88]$.

As shown in Figure 12b, degradation efficiency of bare (CCA1, CCA2, CCA3 and CCA4) and supported ternary nanocomposite over $\mathrm{MeO}$ was 52.78, 65.97, 69.77, 81.56 and $90.22 \%$ respectively. The photocatalyst comprising polyaniline supported $\mathrm{CdS} / \mathrm{CeO}_{2} / \mathrm{Ag}_{3} \mathrm{PO}_{4} \quad$ (PAST) nanocomposite exhibited much higher percentage degradation (90.22\%) as compared to the other single, binary and naked ternary counterparts. This could be due to efficient charge separation of electron and hole pairs in the excited states that prevents recombination of charge pairs for a longer time under visible irradiation. Also the conducting polymer PANI has an extended $\pi$-conjugated electron system [89], narrow band gap $(2.8 \mathrm{eV})$ semiconductor with high absorption coefficients in the visible light range, and acts as an excellent electron donor and a good hole acceptor when illuminated [90], which makes the PAST highly efficient.
These properties make PANI efficient photosensitizer for various semiconductors and provide more active sites for specific binding of dye molecules in order to enhance the separation efficiency of photogenerated electron-hole pairs and consequently better adsorption, photocatalytic activity and stability of the photocatalyst [91, 92].
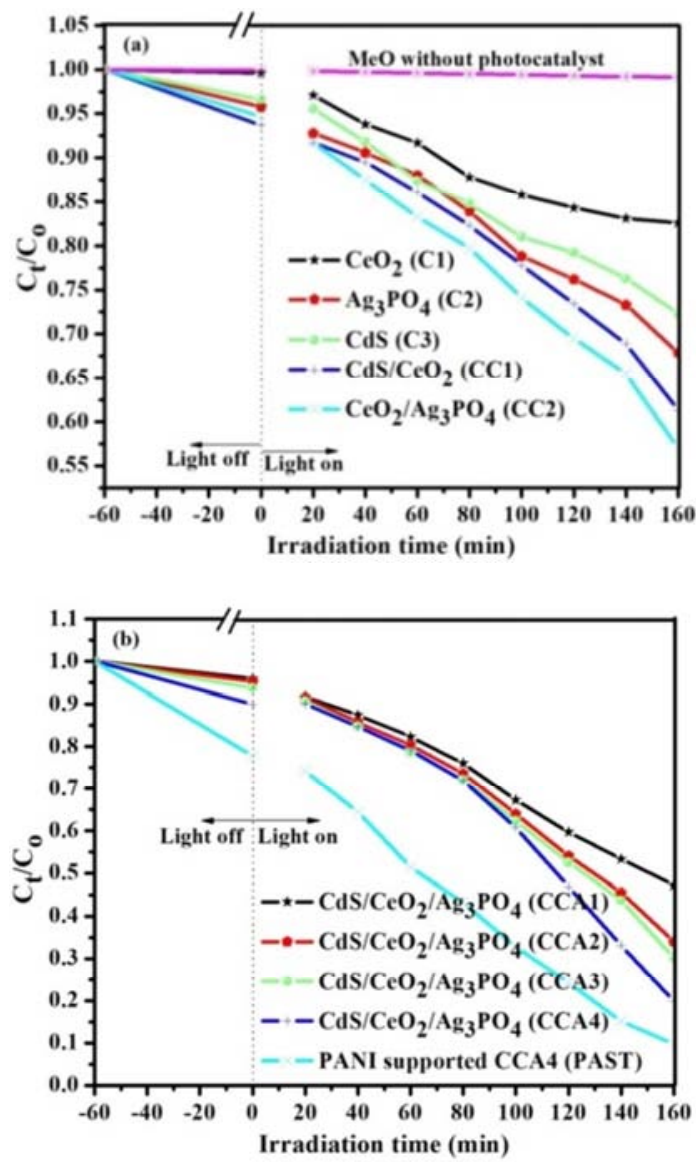

Figure 10. (a) Degradation efficiency of the as-synthesized photocatalyst $\left[\mathrm{CeO}_{2}, \mathrm{Ag}_{3} \mathrm{PO}_{4}, \mathrm{CdS}, \mathrm{CdS} / \mathrm{CeO}_{2}\right.$ and $\left.\mathrm{CeO}_{2} / \mathrm{Ag}_{3} \mathrm{PO}_{4}\right]$ as function of visible irradiation time; (b) Photocatalytic degradation of the as-synthesized bare ternary and supported nanocomposite.

\section{ii. Mechanism of the Photocatalytic Activity of PAST Photocatalyst}

A probable mechanism of charge transfer and photocatalytic degradation of organic pollutant methyl orange $(\mathrm{MeO})$ over the polyaniline supported $\mathrm{CdS} / \mathrm{CeO}_{2} / \mathrm{Ag}_{3} \mathrm{PO}_{4}$ (PAST) nanocomposite under visible light irradiation is put forward and illustrated in Figure 13 [54]. The light illumination on PAST nanocomposite causes the generation of electron (e $\mathrm{e}^{-}$) in conduction band (CB) and holes $\left(\mathrm{h}^{+}\right)$in the valence band (VB).

Indeed, PANI can absorb visible light to induce the $\pi-\pi^{*}$ transition, delivering the excited state electrons of the highest occupied molecular orbital to the lowest unoccupied molecular orbital [93]. PANI produces $\mathrm{e}^{-}$that transfers to the $\mathrm{CB}$ of $\mathrm{CdS} / \mathrm{CeO}_{2} / \mathrm{Ag}_{3} \mathrm{PO}_{4}$ nanocomposite. At $\mathrm{CB}$ site, molecular oxygen $\left(\mathrm{O}_{2}\right)$ forms superoxide radical $\bullet \mathrm{O}_{2}^{-}$in the presence of the photoexcited $\mathrm{CB} \mathrm{e}^{-}$and subsequently reacts with $\mathrm{H}^{+}$to form $\mathrm{HO}_{2} \bullet$ radical species. During the $\mathrm{e}^{-}$transfer 
from PANI to $\mathrm{CB}$ of CCA4, the generated photoinduced $\mathrm{h}^{+}$in VB might react with water $\left(\mathrm{H}_{2} \mathrm{O}\right)$ and the adsorbed $\mathrm{MeO}$ dye molecule to yield hydroxyl radical $(\bullet \mathrm{OH})$ and $\mathrm{MeO} \bullet^{-}$anions radical respectively [94]. The formed $\mathrm{MeO}^{-}$radicals generally transforms to the oxidation and reduction products. On the other hand, electrons in the CCA4 VB can also migrate to the HOMO of PANI and recombine with PANI holes, while the holes generated in the CCA4 VB move to its surface [95]. It is known that these oxygenous radicals $\left(\cdot \mathrm{O}_{2}^{-}\right.$, $\cdot \mathrm{OH}$ and $\mathrm{HO}_{2} \bullet$ ) act as potential oxidizing and reducing species for the degradation of organic molecules (MeO) [96]. The proposed photoreaction mechanism of PAST composite over $\mathrm{MeO}$ degradation under visible light follows:

$$
\mathrm{PAST}+\mathrm{hv} \rightarrow \mathrm{h}_{\mathrm{VB}}^{+}+\mathrm{e}_{\mathrm{CB}}^{-}
$$

Oxidative reaction

$$
\begin{gathered}
\mathrm{h}_{\text {VB }}^{+}+\mathrm{H}_{2} \mathrm{O} \rightarrow \mathrm{H}^{+}+\cdot \mathrm{OH} \\
\cdot \mathrm{OH}+\mathrm{MeO} \rightarrow \text { (Intermediates }) \rightarrow \mathrm{CO}_{2}+\mathrm{H}_{2} \mathrm{O}
\end{gathered}
$$

Reductive reaction

$$
\begin{gathered}
\mathrm{e}_{\mathrm{CB}}^{-}+\mathrm{O}_{2} \rightarrow \cdot \mathrm{O}_{2}{ }^{-} \\
\cdot \mathrm{O}_{2}^{-}+\mathrm{H}^{+} \rightarrow \cdot \mathrm{HO}_{2}
\end{gathered}
$$

$$
\begin{gathered}
\cdot \mathrm{HO}_{2} \rightarrow \cdot \mathrm{O}_{2}^{-}+\mathrm{H}_{2} \mathrm{O}_{2} \\
\cdot \mathrm{O}_{2}{ }^{-}+\mathrm{MeO} \rightarrow(\text { Intermediates }) \rightarrow \mathrm{CO}_{2}+\mathrm{H}_{2} \mathrm{O}
\end{gathered}
$$

Generally:

$\cdot \mathrm{O}_{2}{ }^{-}\left(\cdot \mathrm{OH}, \mathrm{h}^{+}\right)+\mathrm{MeO}+\mathrm{O}_{2} / \mathrm{H}_{2} \mathrm{O} \rightarrow$ Degradation products

The conducting PANI on the surface of CCA4 could absorb photons in the visible light which leads to an efficient photogenerated $\mathrm{e}^{-} \mathrm{h}^{+}$pairs charge separation in semiconductors and increases the lifetime of the photogenerated $\mathrm{e}^{-}-\mathrm{h}^{+}$pairs for diffusing the $\mathrm{MeO}$ dye surface. As a result, PAST nanocomposite delivers high photogenerated $\mathrm{e}^{-}-\mathrm{h}^{+}$pair charge separation and produces sufficiently high amount of radicals for the high degradation of $\mathrm{MeO}$ dye under visible light irradiation. The photocatalytic performance of the photocatalyst mainly depends on: (i) its light absorption properties; (ii) the rates of reduction and oxidation on the surface of the catalyst by the electrons and holes; and (iii) the electron-hole recombination rate [97]. These factor results $93.99 \%$ of $\mathrm{MeO}$ was degraded at optimum $\mathrm{pH}$, initial dye concentration and photocatalyst load under the visible light irradiation.

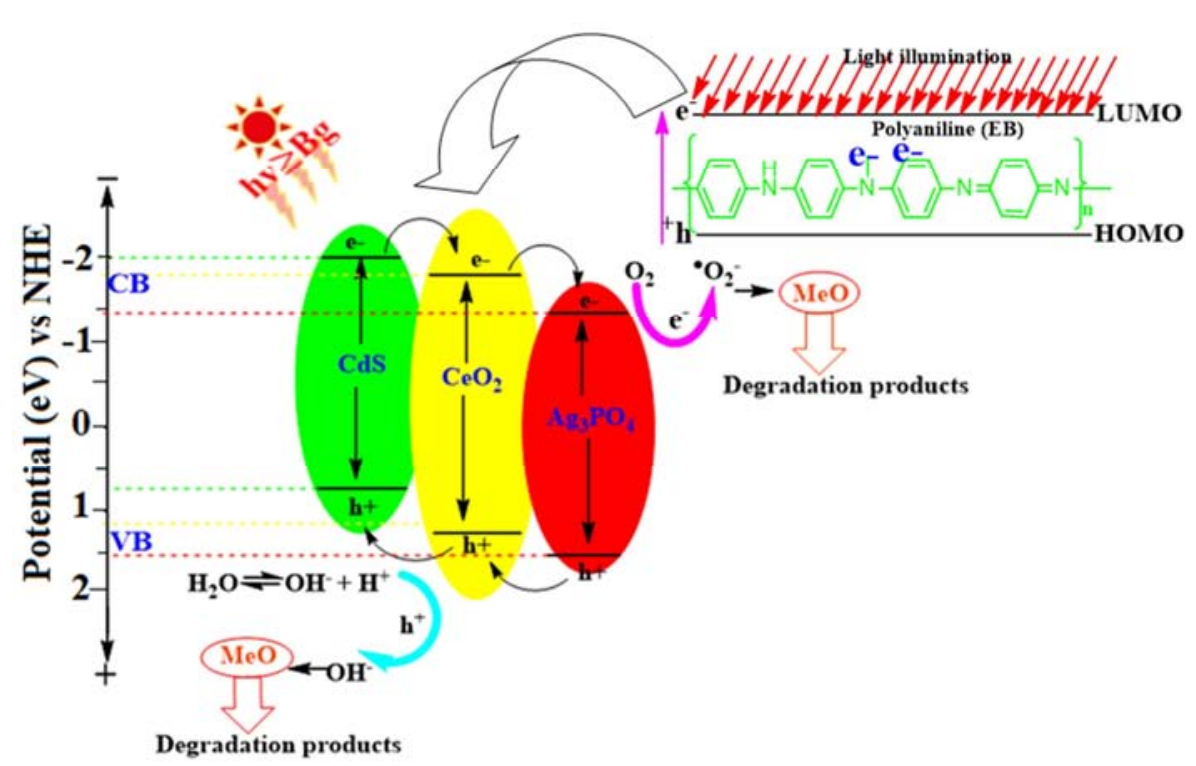

Figure 11. Mechanism of photocatalytic degradation of organic contaminant (MeO) by PAST photocatalyst under visible light irradiation.

\section{Conclusion and Future Trends}

These review was aimed to evaluate the potential of Ceria $\left(\mathrm{CeO}_{2}\right)$ based photocatalyst for photocatalytic wastewater treatment. Coupled nanocomposites namely single, binary and ternary were studied. Photocatalytic degradation activities of the nanocomposite under UV or visible light irradiation have been evaluated for different model pollutant. This review demonstrated that coupling is useful to improve the photocatalytic performance of the photocatalysts for degradation of hazardous chemicals. Also it provides a systematic concept about how coupling contribute to improving the performance of composite photocatalysts. Coupled nanostructured $\mathrm{CeO}_{2}$ have been reported to result in improved degradation rates due to their modified band gap energy for using visible and solar radiation. More studies needs to be carried out in this area to design efficient photocatalytic materials by tuning their band gap to obtain synergistic structure property relationship. Majority of the studies reveals that different supporting materials (either doping or coupling) act as effective sensitizers for $\mathrm{CeO}_{2}$.

So, we need to focus for developing more reliable photocatalysts which can absorb visible and solar radiation or 
by both.

1) The author recommends other researchers to pay attention for advancing further research on this particular area by extending their modification to improve absorption of light.

2) Looking for other polymeric or inorganic supports or organic/inorganic doped to enhance the photocatalytic efficiency.

3) Supporting the photocatalyst by conductive polymers are also possible solving routes to increase the lifetime of the photo-produced electron-hole pairs and improvement of the photocatalytic activity of ceria.

4) Study on the effect of operational parameters such as $\mathrm{pH}$, initial dye concentration, photocatalyst load, light intensity, calcination temperature, and effect of surface area of a photocatalyst on the photocatalytic degradation of organic pollutants.

5) For this a successful collaboration of chemical engineers and chemists is required which would provide better insight and solutions to issues that are hindering commercialization of doping or coupling $\mathrm{CeO}_{2}$ photocatalysts.

\section{Competing Interests}

The author declares that there is no competing interest.

\section{Acknowledgements}

Above all, I would like to extend my special thanks to Dr. Abi Taddesse, for his encouragement and genuine support on the knowledge of nanotechnology. I am indebted to the College of Natural and Computational Sciences and Department of Chemistry in Mekdela Amba University for their contributions in the process of developing the review and provision of various services as well as for providing me a great opportunity to advance intellectually.

\section{References}

[1] Han, F, Kambala, V. S. R, Srinivasan, M, Rajarathnam, D. and Naidu, R. 2009. Tailored titanium dioxide photocatalysts for the degradation of organic dyes in wastewater treatment: A review. Applied Catalysis A, 359: 25-40.

[2] Gogate, P. R. and Pandit, A. B. 2004. A review of imperative technologies for wastewater treatment I: oxidation technologies at ambient conditions. Advance in environmental research, 8: 501-551.

[3] Chen, H. and Zhao, J. 2009. Adsorption study for removal of Congo red anionic dye using organo-attapulgite. Adsorption, 15 (4): 381-389.

[4] Ong, S. T., Keng, P. S., Lee, W. N., Ha, S. T. and Hung, Y. T. 2011. Dye waste water treatment. Water review 3: 157-176.

[5] Huo, S. H. and Yan, X. P. 2012. Metal-organic framework MIL-100 (Fe) for the adsorption of malachite green from aqueous solution. Journal of Materials Chemistry, 22: 7449-
7455.

[6] Brown, M. A. and De Vito, S. C. 1993. Predicting azo dye toxicity. Critical Reviews in Environmental Science and Technology, 23: 249-324.

[7] Kornaros, M. and Lyberatos, G. 2006. Biological treatment of wastewaters from a dye manufacturing company using a trickling filter. Journal of Hazardous Material, 136: 95 102.

[8] Chen, C., Ma, W. and Zhao, J. 2010. Semiconductor-mediated photodegradation of pollutants under visible-light irradiation. Chemical Society Reviews, 39 (11): 4206-4219.

[9] Kubacka, A., Fernandez-Garcia, M. and Colon, G. 2011. Advanced nano-architectures for solar photocatalytic applications. Chemical Reviews, 112 (3): 1555-1614.

[10] Dolbecq, A., Mialane, P., Keita, B. and Nadjo, L. 2012. Polyoxometalate-based materials for efficient solar and visible light harvesting: application to the photocatalytic degradation of azo dyes. Journal of Materials Chemistry, 22 (47): 2450924521.

[11] Fan, W., Zhang, Q. and Wang, Y. 2013. Semiconductor-based nanocomposites for photocatalytic $\mathrm{H}_{2}$ production and $\mathrm{CO}_{2}$ conversion. Physical Chemistry Chemical Physics, 15 (8): 2632-2649.

[12] Anandan, S., Vinu, A., Mori, T., Gokulakrishnan, N., Srinivasu, P., Murugesan, V. and Ariga, K. 2007. Photocatalytic degradation of 2, 4, 6-trichlorophenol using lanthanum doped $\mathrm{ZnO}$ in aqueous suspension. Catalysis Communications, 8 (9): 1377-1382.

[13] Hoffmann, M. R., Martin, S. T., Choi, W. and Bahnemann, D. W. 1995. Environmental applications of semiconductor photocatalysis. Chemical Reviews, 95 (1): 69-96.

[14] Asahi, R., Morikawa, T., Ohwaki, T., Aoki, K. and Taga, Y. 2001. Visible-light photocatalysis in Nitrogen-Doped Titanium Oxides. Science, 293: 269-271.

[15] Bi, Y., Ouyang, S., Cao, J. and Ye, J. 2011. Facile synthesis of rhombic dodecahedral $\mathrm{AgX} / \mathrm{Ag}_{3} \mathrm{PO}_{4} \quad(\mathrm{X}=\mathrm{Cl}, \mathrm{Br}, \quad \mathrm{I})$ heterocrystals with enhanced photocatalytic properties and stabilities. Physical Chemistry Chemical Physics, 13 (21): 10071-10075.

[16] Montini, T., Gombac, V., Hameed, A., Felisari, L., Adami, G. and Fornasiero, P. 2010. Synthesis, characterization and photocatalytic performance of transition metal tungstates. Chemical Physics Letter, 498: 113-119.

[17] Bi, Y., Hu, H., Ouyang, S., Lu, G., Cao, J. and Ye, J. 2012. Photocatalytic and photoelectric properties of cubic $\mathrm{Ag}_{3} \mathrm{PO}_{4}$ sub-microcrystals with sharp corners and edges. Chemical Communications, 48 (31): 3748-3750.

[18] Ran, J., Yu, J. G. and Jaroniec, M. 2011. Ni(OH $)_{2}$ modified $\mathrm{CdS}$ nanorods for highly efficient visible-light-driven photocatalytic $\mathrm{H}_{2}$ generation. Green Chemistry, 13: 27082713.

[19] Wang. Y., Xiuli., Wan, Y. and Fan, C. 2013. Novel visiblelight $\mathrm{AgBr} / \mathrm{Ag}_{3} \mathrm{PO}_{4}$ hybrid's photocatalysts with surface plasma resonance effects. Journal of Solid State Chemistry, 2002: 51-56. 
[20] Wang, H., Zhang, L., Chen, Z., Hu, J., Li, S., Wang, Z., Liu, J. and Wang, X. 2014. Semiconductor heterojunction photocatalysts: design, construction, and photocatalytic performances. Chemical Society Reviews, 43: 5234-5244.

[21] Dana, D., Vlasta, B., Mazur, M. and Malati, M. A. 2002. Investigations of metal-doped titanium dioxide photocatalysts. Applied Catalysis, 37: 91-105.

[22] Liu, Y., He, L., Mustapha, A., Li, H., Hu, ZQ., Lin, M. 2009. Antibacterial activities of zinc oxide nanoparticles against Escherichia coli. Journal of Applied Microbiology, 015 (107): 1193-1201.

[23] Zhang, M., An, T., Liu, X., Hu, X., and Sheng, G. 2010. Rapid large scale preparation of $\mathrm{ZnO}$ nanowires for photocatalytic application. Journal of Nanoscale Research Letters, 64: 18831886.

[24] Tesfay, Wolderufael., O. P., Yadav, and Abi M, Taddesse, 2013. Synthesis, characterization and photocatalytic activity of AgNcodoped $\mathrm{ZnO}$ nanoparticles towards methyl red degradation. Bulletin Chemical Society of Ethiopia, 27: 221-232.

[25] Alebel, Nibret, O. P., Yadav., Isabel, Diaz, and Abi M, Taddesse, 2015. Cr-N Co-doped ZnO nanoparticles: synthesis, characterization and photocatalytic activity for degradation of Thymol blue. Bulletin Chemical Society Ethiopia, 29 (2): 247-258

[26] Haile Hasana, Abi Tadesse. and Tesfahun Kebede. 2015. Synthesis, characterization and photocatalytic activity of $\mathrm{MnO}_{2} / \mathrm{Al}_{2} \mathrm{O}_{3} / \mathrm{Fe}_{2} \mathrm{O}_{3}$ nanocomposite for degradation of malachite green. African Journal of Pure and Applied Chemistry, 9 (11): 211-222.

[27] Shamaila, S., Sajjad, A. K. L., Chen, F. and Zhang, J. 2011. $\mathrm{WO}_{3} / \mathrm{BiOCl}$ a novel heterojunctions visible light photocatalyst. Journal of colloids and interface Science, 356: 465-472.

[28] Stylidi, M., Kondarides, D. I. and Verykios, X. E. 2004. Visible light-induced photocatalytic degradation of Acid Orange 7 in aqueous $\mathrm{TiO}_{2}$ suspensions. Applied Catalysis B: Environmental, 47 (3): 189-201.

[29] Colmenares, J. C., Aramendia, M. A., Marinas, A., Marinas, J. M. and Urbano. F. J. 2006. Synthesis, characterization and photocatalytic activity of different metal doped Titania systems. Applied Catalysis, 306: 120-127.

[30] Curco, D., Gimenez, J., Addardak, A., Cervera-March, S. and Esplugas, S. 2002. Effects of radiation absorption and catalyst concentration on the photocatalytic degradation of pollutants. Catalysis Today, 76: 177-188.

[31] Palmisan, G., Addam, M., Augugliar, V., Caronna, T., Di Paola, A., Lopez, E. G., Lodd, V., Marci, G., Palmisan, L. and Schiavell, M. 2007. Selectivity of hydroxyl radical in the partial oxidation of aromatic compounds in heterogeneous photocatalysis. Catalysis Today, 122: 118-127.

[32] Wang, S. P., Zhao, L. F., Wang, W., Zhao, Y. J., Zhang, G. L., Ma, X. B. and Gong, J. L. 2013. Morphology control of ceria nanocrystals for catalytic conversion of $\mathrm{CO}_{2}$ with methanol. Nanoscale, 5: 5582-5588.

[33] Sun, C., Li, H. and Chen, L. 2012. Nanostructured ceria-based materials: synthesis, properties, and applications. Energy and Environmental Science, 5 (9): 8475-8505.

[34] Magesh, G., Viswanathan, B., Viswanath, R. P. and Varadarajan, T. K. 2009. Photocatalytic behavior of $\mathrm{CeO}_{2-}$
$\mathrm{TiO}_{2}$ system for the degradation of methylene blue. Indian Journal of Chemicals, B. 3: 480-488.

[35] Umezawa, N., Shuxin, O. and Ye, J. 2011. Theoretical study of high photocatalytic performance of $\mathrm{Ag}_{3} \mathrm{PO}_{4}$. Physical review, B. 83: 035202 .

[36] Khan, A., Qamar, M. and Muneer, M. 2012. Synthesis of highly active visible-light-driven colloidal silver orthophosphate. Chemical Physics Letters, 519-520: 54-58.

[37] Ge, M., Zhu, N., Zhao, Y., Li, J. and Liu, L. 2012. Sunlightassisted degradation of dye pollutants in $\mathrm{Ag} 3 \mathrm{PO} 4$ suspension. Industrial and Engineering Chemistry Research, 51 (14): 5167-5173.

[38] Dong, P., Wang, Y., Li, H., Li, H., Ma, X. and Han, L. 2013. Shape-controllable synthesis and morphology-dependent photocatalytic properties of $\mathrm{Ag}_{3} \mathrm{PO}_{4}$ crystals. Journal of Materials Chemistry. A, Materials for Energy and Sustainability, 1 (15): 4651.

[39] Yi, Z., Ye, J., Kikugawa, N., Kako, T., Ouyang, S. and Williams, S. H. 2010. An orthophosphate semiconductor with photooxidation properties under visible-light irradiation. Nature Materials, 9 (7): 559-564.

[40] Erra, S., Shivakumar, C., Zhao, H., Barri, K., Morel, D. L. and Frekides, C. S. 2007. An effective method of Cd incorporation in CdS solar cells for improved stability. Thin Solid Films, 515: 5833.

[41] Preethy, C., Kumari, P. and Sudheer, S. K. 2014. Photocatalytic activation of CdS NPs under visible light for environmental cleanup and disinfection. Solar Energy, 105: 542-547.

[42] Lu, X., Zhai, T., Cui, H., Shi, J., Xie, S., Huang, Y., Liang, C. and Tong, Y. 2011. Redox cycles promoting photocatalytic hydrogen evolution of $\mathrm{CeO}_{2}$ nanorods. Journals of Material Chemistry, 21 (15): 5569-5572.

[43] Ji, P., Zhang, J., Chen, F. and Anpo, M. 2009. Study of adsorption and degradation of Acid Orange 7 on the surface of $\mathrm{CeO}_{2}$ under visible light irradiation. Applied Catalysis B, 85 (3-4), 148-154.

[44] Primo, A., Marino, T., Corma, A., Molinari, R. and Garcia, H. 2011. Efficient visible-light photocatalytic water splitting by minute amounts of gold supported on Nanoparticulate $\mathrm{CeO}_{2}$ obtained by a biopolymer Templating method. Journal of American Chemical Society, 133 (18): 6930-6933.

[45] Feng, Y. J., Liu, L. L. and Wang, X. D. 2011. Hydrothermal synthesis and automotive exhaust catalytic performance of $\mathrm{CeO}_{2}$ nanotube arrays. Journal of Material Chemistry, 21 (39): $15442-15448$

[46] Hu, S., Zhou, F., Wang, L. and Zhang, J. 2011. Preparation of $\mathrm{Cu}_{2} \mathrm{O} / \mathrm{CeO}_{2}$ heterojunction photocatalyst for the degradation of Acid Orange 7 under visible light irradiation. Catalysis Communication, 12 (9): 794-797.

[47] Yue, L. and Zhang, X. M. 2009. Structural characterization and photocatalytic behaviors of doped $\mathrm{CeO}_{2}$ nanoparticles. Journal of Alloys Compound, 475 (1-2): 702-705.

[48] Zhang, J., Li, L., Huang, X. and Li, G. 2012. Fabrication of Ag$\mathrm{CeO}_{2}$ core-shell nanospheres with enhanced catalytic performance due to strengthening of the interfacial interactions. Journal of Material Chemistry, 22 (21): 10480-10487. 
[49] Ijaz, S., Ehsan, M. F., Ashiq, M. N., Karamat, N. and He, T. 2016. Preparation of $\mathrm{CdS} / \mathrm{CeO}_{2}$ core/shell composite for photocatalytic reduction of $\mathrm{CO}_{2}$ under visible-light irradiation. Applied Surface Science, 390: 550-559.

[50] Song, Y., Zhao, H., Chen, Z., Wang, W., Huang, L., Xu, H. and $\mathrm{Li}, \mathrm{H}$. 2016. The $\mathrm{CeO}_{2} / \mathrm{Ag}_{3} \mathrm{PO}_{4}$ photocatalyst with stability and high photocatalytic activity under visible light irradiation. Physical Status Solidi A, 213 (9): 2356-2363.

[51] Velusamy, P. and Lakshmi, G. 2017. Enhanced photocatalytic performance of $\left(\mathrm{ZnO} / \mathrm{CeO}_{2}\right)-b-\mathrm{CD}$ system for the effective decolorization of Rhodamine B under UV light irradiation. Applied Water Science, 7: 4025-4036.

[52] Saikia, P., Miah, A. T. and Das, P. P. 2017. Highly efficient catalytic reductive degradation of various organic dyes by $\mathrm{Au} / \mathrm{CeO}_{2}-\mathrm{TiO}_{2}$ nano-hybrid. Journal of Chemical Sciences, 129 (1): 81-93.

[53] Milenova, K., Zaharieva, K., Stambolova, I., Blaskov, V., Eliyas, A. and Dimitrov. L. 2017. Photocatalytic performance of $\mathrm{TiO}_{2}, \mathrm{CeO}_{2}, \mathrm{ZnO}$ and $\mathrm{TiO}_{2}-\mathrm{CeO}_{2}-\mathrm{ZnO}$ in the course of methyl orange dye degradation. Journal of Chemical Technology and Metallurgy, 52 (1): 13-19.

[54] Abi M. Taddesse., Tigabu Bekele., Isabel Diaz. and Abebaw Adgo. 2021. Polyaniline supported $\mathrm{CdS} / \mathrm{CeO}_{2} / \mathrm{Ag}_{3} \mathrm{PO}_{4}$ nanocomposite: An "A-B" type tandem n-n heterojunctions with enhanced photocatalytic activity. Journal of Photochemistry and Photobiology, A: Chemistry, 406: 113005.

[55] Pouretedal, H. R., Tofangsazi, Z. and Keshavarz, M. H. 2012. Photocatalytic activity of mixture of $\mathrm{ZrO}_{2} / \mathrm{SnO}_{2}, \mathrm{ZrO}_{2} / \mathrm{CeO}_{2}$ and $\mathrm{SnO}_{2} / \mathrm{CeO}_{2}$ nanoparticles. Journal of Alloys Compound, 513: 359-364.

[56] Yao, W., Zhang, B., Huang, C., Ma, C., Song, X. and Xu, Q. 2012. Synthesis and characterization of high efficiency and stable $\mathrm{Ag}_{3} \mathrm{PO}_{4} / \mathrm{TiO}_{2}$ visible light photocatalyst for the degradation of methylene blue and Rhodamine B solutions. Journal of Material Chemistry, 22 (9): 4050- 4055.

[57] Bamwenda, G. R and Arakawa, H. J. 2000. Cerium dioxide as a photocatalyst for water decomposition to $\mathrm{O}_{2}$ in the presence of $\mathrm{Ce}^{4+}$ aq and $\mathrm{Fe}^{3+}$ aq species. Molecular Catalysis A: Chemistry, 161: 105-113.

[58] Hernandez-Alonso, M. D., Hungria, A. B., Martınez-Arias, A., Fernandez-Garcia, M., Coronado, J. M., Conesa, J. C. and Soria, J. 2004. EPR study of the photoassisted formation of radicals on $\mathrm{CeO}_{2}$ nanoparticles employed for toluene photooxidation. Applied Catalysis B: Environmental, 50 (3): 167-175.

[59] Zhai, Y. Q., Zhang, S. Y. and Pang, H. 2007. Preparation, characterization and photocatalytic activity of cerium oxide nanocrystalline using ammonium bicarbonate as precipitant. Materials Letters, 61: 1863-1866.

[60] Salker, A. V. and Borker, P. 2007. Solar assisted photocatalytic degradation of Naphthol Blue Black dye using $\mathrm{Ce}_{1-\mathrm{x}} \mathrm{Mn}_{\mathrm{x}} \mathrm{O}_{2}$. Materials chemistry and physics, 103 (2-3): 366370 .

[61] Huang, G. F., Ma, Z. L., Huang, W. Q., Tian, Y., Jiao, C., Yang, Z. M., Wan, Z. and Pan, A. 2013. $\mathrm{Ag}_{3} \mathrm{PO}_{4}$ Semiconductor Photocatalyst: Possibilities and Challenges. Journal of Nanomaterials, 2013 (8): 371356.
[62] Yang, Z. M., Huang, G. F., Huang, W. Q., Wei, J. M., Yan, X. G. and Liu, Y. Y. 2014. Novel $\mathrm{Ag}_{3} \mathrm{PO}_{4} / \mathrm{CeO}_{2}$ composite with high efficiency and stability for photocatalytic applications. Journal of Materials Chemistry A, 2: 1750-1756.

[63] Zhang, W., Hu, C., Zhai, W., Wang, Z., Sun, Y., Chi, F., Ran, S., Liu, X. and Lv, Y. 2016. Novel $\mathrm{Ag}_{3} \mathrm{PO}_{4} / \mathrm{CeO}_{2}$ p-n hierarchical heterojunction with enhanced photocatalytic performance. Materials Research, 19 (3): 673-679.

[64] Barpuzary, D. and Qureshi, M. 2013. Enhanced photovoltaic performance of semiconductor- sensitized $\mathrm{ZnO}-\mathrm{CdS}$ coupled with graphene oxide as a novel photoactive material. ACS Applied Material Interfaces, 5: 11673-11682.

[65] Thakur, P. and Chadha, R. 2012. Synthesis and characterization of $\mathrm{CdS}$ doped $\mathrm{TiO}_{2}$ nanocrystalline powder: a spectroscopic study. Material Research Bulletin, 47: 17191724.

[66] Li, W., Xie, S., Li, M., Ouyang, X., Cui, G., Lu, X. and Tong, Y. 2013. $\mathrm{CdS} / \mathrm{CeOx}$ heterostructured nanowires for photocatalytic hydrogen production. Journal of Material Chemistry A, 1: 4190-4193.

[67] Gu, S., Chen, Y., Yuan, X., Wang, H., Chen, X., Liu, Y., Jiang, Q., Wu, Z. and Zeng, G. 2016. Facile synthesis of $\mathrm{CeO}_{2}$ nanoparticle sensitized $\mathrm{CdS}$ nanorod photocatalyst with improved visible light photocatalytic degradation of Rhodamine B. RSC Advances, 5: 79556-79564.

[68] You, D. T., Pan, B., Jiang, F., Zhou, Y. G. and Su, W. Y. 2016. $\mathrm{CdS}$ nanoparticles $/ \mathrm{CeO}_{2}$ nanorods composite with highefficiency visible-light-driven photocatalytic activity. Applied Surface Science, 363: 154-160.

[69] Zhang, X., Zhang, N., Xu, Y. and Tang, Z. R. 2015. Onedimensional $\mathrm{CdS}$ nanowires $\mathrm{CeO}_{2}$ nanoparticles composites with boosted photocatalytic activity. New Journal of Chemistry, 39: 6756-6764.

[70] Xu, A. W., Gao, Y. and Liu, H. Q. 2002. The preparation, characterization, and their photocatalytic activities of rareearth-doped $\mathrm{TiO}_{2}$ nanoparticles. Journals of Catalysis, 207: 151-157.

[71] Wang, L., Ding, J., Chai, Y., Liu, Q., Ren, J., Liu, X. and Dai, W. L. 2015. $\mathrm{CeO}_{2}$ nanorod $/ \mathrm{g}-\mathrm{C}_{3} \mathrm{~N}_{4} / \mathrm{N}-\mathrm{rGO}$ composite: enhanced visible-light-driven photocatalytic performance and the role of N-rGO as electronic transfer media. Dalton Transactions, 44: 11223-11234.

[72] Wang, J., Fan, H., Chen, W., Jiao, Y., Jin, W., Zhao, Y., Zhang, S. and Yao, H. 2011. Synergistic effect of $\mathrm{CeO}_{2}$ modified $\mathrm{TiO}_{2}$ photocatalyst on the enhancement of visible light photocatalytic performance. Journal of the Chinese Ceramic Society, 39: 2002-2007.

[73] Chen, F., Ho, P., Ran, R., Chen, W., Si, Z., Wu, X., Weng, D., Huang, Z. and Lee, C. 2017. Synergistic effect of $\mathrm{CeO}_{2}$ modified $\mathrm{TiO}_{2}$ photocatalyst on the enhancement of visible light photocatalytic performance. Journal of Alloys and Compounds, doi: 10.1016/j.jallcom.2017.04.138.

[74] Chen, C., Zhao, W., Lei, P., Zhao, J. and Serpone, N. 2004. Photosensitized degradation of dyes in Polyoxometalate solutions versus $\mathrm{TiO}_{2}$ dispersions under visible-light irradiation: mechanistic implications. Chemical European Journals, 10: 1956-1965. 
[75] Torreshuerta, A. M., Dominguezcrespo, M. A., Brachettisibaj, S. B., Dorantesrosales, H. J., Hernandezperez, M. A. and Loiscorre, J. A. 2010. Preparation of $\mathrm{ZnO}: \mathrm{CeO}_{2-\mathrm{x}}$ thin films by AP-MOCVD: structural and optical properties. Journal of Solid State Chemistry, 183 (9): 2205-2217.

[76] Ma, T. Y., Yuan, Z. Y. and Cao, J. L. 2010. Hydrangea-like meso/macroporous $\mathrm{ZnO}-\mathrm{CeO}_{2}$ binary oxide materials: synthesis, photocatalysis and co-oxidation. European Journal of Inorganic Chemistry, 5: 716-724.

[77] De Lima, J. F., Martins, R. F., Neri, C R. and Serra, O. A. 2009. $\mathrm{ZnO}: \mathrm{CeO}_{2}$-based nanopowders with low catalytic activity as UV absorbers. Applied Surface Science, 255 (22): 9006-9009.

[78] Mo, L. Y., Zheng, X. M. and Yeh, C. T. 2005. A novel $\mathrm{CeO}_{2} / \mathrm{ZnO}$ catalyst for hydrogen production from the partial oxidation of methanol. Chemical Physics Chemistry, 6 (8): 1470-1472.

[79] Nidhi, H., Shah, Karan, R., Bhangaonkar, S. and Mhaske, T. 2017. In-Situ Synthesis of $\mathrm{CeO}_{2} / \mathrm{ZnO}$ composite nanoparticles and its application in degradation of Rhodamine B using Sonocatalytic and photocatalytic method. International Journal of Materials Science and Engineering, 5 (1): 16-27.

[80] Rodwihok, C., Wongratanaphisan, D., Tam, T. V., Choi, W. M., Hur, S. H. and Chung, J. S. 2020. Cerium-oxide-nanoparticledecorated zinc oxide with enhanced photocatalytic degradation of methyl orange. Applied Science, 10: 1697.

[81] Yuan, Y., Huang, G. F., Hu, W. Y., Xiong, DN., Zhou, B. X., Chang, S. and Huang, W. Q. 2017. Construction of g$\mathrm{C}_{3} \mathrm{~N}_{4} / \mathrm{CeO}_{2} / \mathrm{ZnO}$ ternary photocatalysts with enhanced photocatalytic performance. Journal of Physics and Chemistry of Solids, 106: 1-9.

[82] Prabhu, S., Viswanathan, T., Jothivenkatachalam, K. and Jeganathan, K. 2014. Visible light photocatalytic activity of $\mathrm{CeO}_{2}-\mathrm{ZnO}-\mathrm{TiO}_{2}$ composites for the degradation of Rhodamine B. Indian Journal of Materials Science, doi.org/10.1155/2014/536123.

[83] Pan, H., Haoxi, J. and Minhua, Z. 2012. Structures and oxygen storage capacities of $\mathrm{CeO}_{2}-\mathrm{ZrO}_{2}-\mathrm{Al}_{2} \mathrm{O}_{3}$ ternary oxides prepared by a green route: supercritical anti-solvent precipitation. Journal of Rare Earths, 30 (6): 524.

[84] Reddy, B. M., Lakshmanan, P. and Khan, A. 2004. Investigation of surface structures of dispersed $\mathrm{V}_{2} \mathrm{O}_{5}$ on $\mathrm{CeO}_{2}-$ $\mathrm{SiO}_{2}, \mathrm{CeO}_{2}-\mathrm{TiO}_{2}$ and $\mathrm{CeO}_{2}-\mathrm{ZrO}_{2}$ mixed oxides by XRD, Raman, and XPS techniques. Journal of Physical Chemistry B, 108 (43): 16855-16863.

[85] Reddy, B. M., Khan, A., Lakshmanan, P., Aouine, M., Loridant, S. and Volta, J. C. 2005. Structural characterization of nanosized $\mathrm{CeO}_{2}-\mathrm{SiO}_{2}, \mathrm{CeO}_{2}-\mathrm{TiO}_{2}$, and $\mathrm{CeO}_{2}-\mathrm{ZrO}_{2}$ catalysts by XRD, Raman, and HREM techniques. Journal of Physical Chemistry B, 109 (8): 3355-3363.
[86] Berg, J. M., Romozer, A., Banerjee, N. and Sayes, C. M. 2009. The relationship between $\mathrm{pH}$ and zeta potential of $30 \mathrm{~nm}$ metal oxide nanoparticle suspensions relevant to in vitro toxicological evaluations. Nanotoxicology, 3: 276-283.

[87] Haileyesus, Tedla., Isabel, Diaz., Tesfahun, Kebede., Abi M, Taddesse. 2015. Synthesis, characterization and photocatalytic activity of zeolite supported $\mathrm{ZnO} / \mathrm{Fe}_{2} \mathrm{O}_{3} / \mathrm{MnO}_{2}$ nanocomposite. Journal of Environmental Chemical Engineering, 3: 15861591.

[88] Jin, C., Liu, G., Zu, L., Qin, Y. and Yang, J. 2015. Preparation of $\mathrm{Ag} / \mathrm{Ag}_{3} \mathrm{PO}_{4} / \mathrm{ZnO}$ ternary heterostructured for photocatalytic studies. Journal of Colloid and Interface Science, 453: 36-41.

[89] Lee, K., Cho, S., Park, S. H., Heeger, A. J., Lee, C. W. and Lee, S. H. 2006. Metallic transport in polyaniline. Nature, 441 (7089): 65-68.

[90] Bu, Y. and Chen, Z. 2014. Role of polyaniline on the photocatalytic degradation and stability performance of the Polyaniline/Silver/Silver Phosphate composite under visible light. American Chemical Society of Applied Material Interfaces, 6 (20): 17589-17598.

[91] Zhang, H., Zong, R., Zhao, J. and Zhu, Y. 2008. Dramatic visible photocatalytic degradation performances due to synergetic effect of $\mathrm{TiO}_{2}$ with PANI. Environmental Science Technology, 42 (10): 3803-3807.

[92] Ge, L., Han, C. and Liu, J. 2012. In situ synthesis and enhanced visible light photocatalytic activities of novel PANI $/ g-C_{3} \mathrm{~N}_{4}$ composite photocatalysts. Journal of Material Chemistry, 22 (23): 11843-11850.

[93] Zhang, L. J. and Wan, M X. 2003. Polyaniline/ $\mathrm{TiO}_{2}$ nanocomposite nanotubes. Journal of Physical Chemistry, 107 (28): 6748-6753.

[94] Fujishima, A., Rao, T. N. and Tryk, D. K. 2000. Titanium dioxide photocatalysis. Journal of Photochemistry and Photobiology C: Photochemistry Reviews, 1 (1): 1-21.

[95] Hidalgo, D., Bocchini, S., Fontana, M., Saraccob, G. and Hernandez, S. 2015. Green and low- cost synthesis of PANI$\mathrm{TiO}_{2}$ nanocomposite mesoporous films for photoelectrochemical water splitting. Royal Society of Chemistry, 5: 49429-49438.

[96] Ameen, A., Akhtar, M. S., Kim, Y. S., Yang, B. and Shin, H. S. 2011. An effective nanocomposite of polyaniline and $\mathrm{ZnO}$ : preparation, characterizations, and its photocatalytic activity. Colloid Polymer Sciences, 289: 415-421.

[97] Li, J., Zhu, L., Wu, Y., Harima, Y., Zhang, A. and Tang, H. 2006. Green and low-cost synthesis of $\mathrm{PANI} / \mathrm{TiO}_{2}$ nanocomposite mesoporous films for photoelectrochemical water splitting. Polymer, 47: 7361-7367. 